\title{
EL ESPACIO TRANSICIONAL COMO PUERTA DE ENTRADA A LA INTERSUBJETIVIDAD ${ }^{1}$
}

\author{
María Cristina Gómez Álvarez² \\ Guadalajara, México \\ E. Alejandra Plaza Espinosa ${ }^{3}$ \\ Mexico D.F., México \\ Steven H. Knoblauch ${ }^{4}$ \\ New York, USA
}

\begin{abstract}
El tratamiento de una estructura mental disociada, plantea Bromberg (2011) requiere de un espacio transicional donde paciente y analista puedan experimentar, en un lugar creativo y seguro, sus estados del self incompatibles y, a la vez, la sensación de alteridad. Un espacio mental, más cercano a un sueño que a la realidad- donde las historias puedan ser nombradas y elaboradas a través de una relación terapéutica que incursione por caminos nunca antes recorridos. El campo interdisciplinario y el psicoanálisis contemporáneo resultan herramientas sumamente valiosas para conceptualizar una arena de juego donde las mentes se puedan encontrar en un diálogo intersubjetivo y el self sea capaz de descubrir -en un íntimo y mutuo despertar de estados disociados- unidad, coherencia y significado.

A modo de ilustración, se presentan dos trabajos -y una discusión de los mismos- que formaron parte de un panel celebrado en la 12ava Conferencia Anual de la IARPP que tuvo lugar en Toronto en junio del 2015. Se agregan unas reflexiones finales, producto de la discusión de los trabajos durante y después del congreso.

Palabras clave: Disociación, espacio transicional, estados "no yo", el tiempo en análisis.
\end{abstract}

According to Bromberg (2011), the treatment of a dissociated mental structure requires a transitional space -a creative and safe place- where patient and analyst may experience their incompatible self-states and, simultaneously, the feeling of otherness. A mental space -closer to a dream than to walking reality- where stories can be named and elaborated on through a therapeutic relation that explores roads never walked upon before. The interdisciplinary field and contemporary psychoanalysis become extremely valuable tools to conceptualize a playground where minds can meet in an intersubjective dialogue and the self is capable of discovering -in an intimate and mutual awakening of dissociated states- self-unity, coherence and meaning. By way of illustration, we present two papers -and a discussion on both of them- that took part of the panel held in the $12^{\text {th }}$ IARPP Annual Conference celebrated in Toronto, Canada, in June 2015. We also add some final reflections that resulted from the discussion of the papers both during and after the congress.

Key Words: Dissociation, transitional space, "not-me" self-states, time in analysis.

English Title: Transitional Space as a Gateway to Intersubjectivity.

\section{Cita bibliográfica / Reference citation:}

Gómez, M.C., Plaza, A. y Knoblauch, S.H.. (2016). El Espacio transicional como puerta de entrada a la intersubjetividad. Clínica e Investigación Relacional, 10 (2): 417-438. [ISSN 1988-2939] [Recuperado de www.ceir.info ] DOI: 10.21110/19882939.2016.100205

\footnotetext{
${ }^{1}$ Versión castellana del Panel del mismo título presentado en la Conferencia Internacional de IARPP en Toronto, Canadá, 28 de Junio de 2015.

${ }^{2}$ Psicoanalista Miembro de la Asociación Psicoanalítica Jalisciense, México (APJ, IPA). cgomezz3@hotmail.com 3 Psicoanalista, Instituto de Investigación en Psicología Clínica y Social. Miembro de IARPP-México (IARPP). Autora de Emoción y Relaciones Humanas con Joan Coderch (Madrid: Ágora Relacional, 2016), entre otros trabajos. aplazaespinosa@yahoo.com

4 Miembro del Board de IARPP. Autor de la obra The Musical Edge of Therapeutic Dialogue (Hillsdale, NJ: The Analyrtic Press, 2000). 


\title{
LAS DIMENSIONES VERBAL Y NO VERBAL DE LA INTERACCIÓN CLÍNICA: UNA VISIÓN INTERDISCIPLINARIA EN EL ABORDAJE DE UNA PACIENTE SEVERAMENTE TRAUMATIZADA
}

\author{
MARIA CRISTINA GÓMEZ ALVAREZ
}

Cuando María ${ }^{1}$ entró a mi consultorio, apenas y podía con todo lo que llevaba cargando: su computadora, una estorbosa mochila y una chamarra que se antojaba demasiado gruesa y mullida para el frío que hacía a esa hora del día. En este momento de reflexión, pienso que María traía cargando, también sobre sus hombros, un pesado y poco claro diagnóstico de "trastorno severo de la personalidad" ante la imposibilidad de los médicos de confirmar, en ese momento, un cuadro esquizofrénico que pudiera estar gestándose.

María, María... ¿Cómo ayudar, me pregunté, a esta joven de 16 años, de grandes ojos vacíos, inexpresivos y largo cabello que escurría por su rostro y cuello? El tono con el que comenzó a hablar sonaba fuerte, hueco, intelectualizado: "Mi problema empezó cuando era muy chica. Tengo ¿ideas, recuerdos? ¿Quizá sueños, pesadillas? -no me queda muy clarode que alguien abusó de mí durante mucho tiempo. Por ahora es todo lo que puedo decir".

Ante el caso de una chica como María, donde el sinsentido y la falta de experiencias subjetivas se ven tan claramente reveladas, sentí que debía remontarme y buscar respuestas en aquellas etapas previas a los símbolos y las palabras; momentos relacionados con lo sensorial, el movimiento, los colores, los olores y texturas de las cosas. Prestar atención a esta dimensión no verbal se vuelve particularmente importante con los llamados "pacientes difíciles" con los que es preciso ir más allá del intercambio verbal normal. Con esto en mente, y buscando enriquecer mi comprensión de este terreno tan primitivo, sentí que necesitaba fomentar un diálogo entre el psicoanálisis relacional contemporáneo y los hallazgos clínicos en neurociencias, psicología cognitiva e investigación del desarrollo en bebés tratando de entretejerlos con el caso de María.

El presente trabajo, parte de una investigación que estoy realizando actualmente para obtener mi doctorado, pretende enfocar los beneficios de un enfoque interdisciplinario en el caso de una paciente severamente trastornada. 


\section{AMPLIANDO EL HORIZONTE}

Beatriz Beebe, Wilma Bucci, Philip Bromberg, Allan Shore y Joan Coderch, entre otros, representan un pensamiento contemporáneo multidisciplinario interesado en explorar nuevas vías de abordar la teoría y el tratamiento en psicoanálisis.

El trabajo de Beebe, (2002) pretende replantear el psicoanálisis dentro de un modelo de interacción paciente/terapeuta -basado en la teoría de sistemas y consistente con investigaciones del desarrollo en bebés y en adultos. Desde esta perspectiva, la interacción se describe como un proceso continuo y de influencia recíproca, construido momento a momento por ambos participantes. Dentro de este proceso, dice Beebe, podemos distinguir dos niveles: el nivel usual del discurso psicoanalítico -que entraña una narrativa simbólica, verbal y explícita- y otro nivel -implícito y no verbal- que se da en paralelo y que también es preciso considerar. El sistema verbal-cuando hablamos y escuchamos- normalmente está en el centro del trabajo y es más intermitente. La dimensión no verbal (miradas, sonidos, sensaciones viscerales) está siempre ahí -al fondo- generada por ambos miembros de la díada. Y, aun cuando esté fuera de la conciencia y sea inaccesible al lenguaje, continúa operando y afectando pensamientos, sentimientos y acciones.

Por otra parte, Bucci (2007, 2011), plantea que los hallazgos en el campo de las neurociencias y la psicología cognitiva han ampliado nuestra comprensión de lo que significa "conocer". Los modelos clásicos de procesamiento de la información estuvieron basados en sistemas simbólicos, pero, en la actualidad, contamos con otros modos conocidos como subsimbólicos. Estos modos abren la puerta a un mundo de pensamiento complejo -que es no verbal e incluso no simbólico- pero que tiene sus propios formatos sistemáticos y organizados -hablamos así de las sensaciones del viento, del sabor del vino, de los matices de la música... Un mundo que está enraizado en nuestros cuerpos y en nuestros sentidos -y que puede ser experimentado y comprendido de forma consciente -pero que no se puede representar directamente en palabras. Las imágenes, que son simbólicas y no verbales, proporcionan el vínculo necesario con el mundo simbólico.

El conocimiento subsimbólico aparece en cientos de acciones comunes, desde reconocer una voz familiar hasta realizar habilidades complejas en el mundo de los deportes, el trabajo creativo en la ciencia y en las artes. El gran escultor "conoce" su arte a través de sus sistemas visuales y táctiles, pero no le es fácil comunicarlo en palabras. Einstein hablaba de experiencias sensoriales y corporales como elementos básicos de su pensamiento. A este proceso subsimbólico lo conocemos coloquialmente como la intuición, la sabiduría del cuerpo. Es la "voz" que nos dice si algo es bueno o malo para nosotros. 
"Se necesitan dos para bailar un tango", dice Bucci (2011), al igual que se necesitan dos para realizar un tratamiento psicoanalítico. En ambos casos, los participantes primero sienten sus cuerpos, luego sienten el cuerpo del otro antes de que ambos construyan el movimiento que sigue. Este es el interjuego de los procesos simbólicos y subsimbólico.

\section{IMPLICACIONES CLÍNICAS}

Si bien el proceso interactivo -noverbal- es importante en cualquier tratamiento, cuando hablamos de pacientes "difíciles de contactar", esta dimensión se vuelve especialmente crítica. Para este tipo de tratamientos se acuñaron términos como "parámetros" e "intervenciones más allá de la interpretación". Estos son los tratamientos en los que el poder terapéutico reside en focalizar el sistema y el proceso que transcurre momento a momento.

La investigación con bebés (Beebe B.,2002) revela que la interacción no verbal-como el encuentro de miradas, el movimiento del cuerpo, la sintonía en los ritmos vocales, los tonos y las pausas, son algunos de los elementos más importantes para experimentar intimidad, vinculación, reconocimiento y contacto profundo con otro ser humano a lo largo de la vida. Aplicar este concepto de interacción al tratamiento de adultos enriquece nuestra visión de la acción terapéutica. Paciente y analista realizan intercambios verbales $y$, en forma paralela, se influyen -momento a momento- en sus espacios, sus tiempos, sus niveles afectivos, para encontrarse o desencontrarse, para decir "vamos -o no- por el mismo camino". Estos dos niveles -que potencialmente se afectan entre sí- deben integrarse a fin de comprender cabalmente la acción terapéutica. El esfuerzo por simbolizar el nivel de acción implícito puede verse como uno de los grandes objetivos del psicoanálisis.

\section{PUERTA DE ENTRADA A LA INTERSUBJETIVIDAD}

Hay muchas formas en las que esta visión de un modelo interactivo de la mente converge con las teorías relacionales e intersubjetivas. Bromberg (2011), dice que se podría pensar en la psicoterapia como en un espacio transicional -más cercano a un sueño que a una realidad- donde paciente y terapeuta pueden despertar y compartir, en un diálogo intersubjetivo, sus múltiples estados del self disociados para irlos integrando gradualmente en una identidad coherente. "Es a través, dice Bromberg, de la intimidad e inmediatez de este mutuo despertar que ocurre el cambio terapéutico" (p. 22).

A partir de la neurociencia y la investigación cognitiva (2007, 2011), sabemos hoy que la intersubjetividad es más que pensamientos que coinciden. Es el encuentro, no sólo de dos 
mentes, sino también de dos cuerpos. El cuerpo es un instrumento que puede escuchar, ver, tocar y oler el mundo que nos rodea y tiene la habilidad de sintonizarse con la música misteriosa y la voz sutil de la psique para encontrar significados en la oscuridad. En palabras de Allan Shore, (2012) el analista, por medio de su intuición y capacidad de rêverie escucha con su cerebro derecho el cerebro derecho del paciente. Renuncia a su intento de "comprender al paciente" y se permite "conocerlo a través de sus sentidos".

Joan Coderch, (2015) nos recuerda que las capas más profundas de la mente humana se han estructurado a través de las experiencias, no simbólicas, no verbales, vividas con la madre. "La única manera de llegar ahí es a través de nuevas experiencias emocionales. La sensación de ser entendido es una buena experiencia para el paciente, pero la mejor experiencia terapéutica es la de ser reconocido. Comprendemos, básicamente, con nuestras funciones cognitivas, pero, reconocemos a los demás a través de nuestras emociones, nuestra respiración, el latido del corazón, nuestros sentidos, con nuestro compromiso y con nuestro amor..." (p.45).

\section{EL CAMINO QUE MARÍA Y YO HEMOS RECORRIDO JUNTAS}

Cuando comencé a ver a María, hace poco más de cinco años, presentaba fuertes crisis de angustia. Al principio, todo lo que intentaba yo, era tratar de conectarme con ella de alguna manera.

\section{UN PRIMER ESPACIO DE IMPRESIONES SENSORIALES}

Desde siempre, la voz de María, ha sido una voz pobremente articulada, carente de matices y tonos afectivos; una voz, monótona, casi imperceptible, que pareciera no querer revelarse. Su rostro, impactantemente inexpresivo. Sus ojos vacíos, taladran el corazón. Este cuadro tan desprovisto de humanidad me hablaba, con desesperación, de la imposibilidad de establecer contacto con María. Sin pensarlo, un día le dije que si podía sentarme más cerca de ella, en el sofá o en el suelo, no importaba, sólo quería acercarme, escucharla y verla mejor. "¿Sabes María?", le dije, "siento que tu mirada me pide ayuda desesperada". "Puede ser", me contestó. Algo pasó ese día que la descripción de su rostro se volvió una costumbre, otro ritual, al inicio de la sesión. Tras disponer todas sus cosas en el sofá, lo primero que hacía era voltear a verme fijamente, sin decir palabra. Yo sabía que buscaba que "le interpretara su mirada". Sin proponérmelo de forma consciente, y sin mediar otro tipo de diálogo, comencé a hablarle, no sólo de lo que veía en su mirada, sino de lo que me decía la forma arqueada de sus cejas, la posición de sus párpados, la tirantez o flexibilidad de los músculos de su rostro. A medida que le hablaba, instintivamente comencé también a tocar mi rostro. Me di cuenta 
cómo iba modulando mi voz para acompañar mis palabras en un intento de transmitirle lo que sentía. Comencé también a incluir mi cuerpo, la opresión que sentía en el pecho, la tensión de mi cuello. De algún modo, sentía que ambas nos sentíamos conectadas.

Muy pronto sentí que tenía que dejar de preguntarle a María sobre su historia y los abusos de que fue objeto. La veía tan exigida por todo que comencé a dejarla decidir lo que haríamos: a veces era oír música, jugar un videojuego, platicar sobre sus mascotas, guardar silencio mientras su mirada se perdía. Una vez, sentí que María venía extremadamente cansada. ¿Quieres dormir?" le pregunté sin pensar. Asintió con la cabeza y le ofrecí el sofá, el cojín de una silla, la cobija que cubre el diván y la posibilidad de subir los pies al sillón. Durmió profundamente toda la sesión. Otro día llegó con una fuerte gripa y con su almohada en mano. Se me hizo obvio que quería dormir. La desperté al final de la sesión sólo para decirle que sentía que algo pasaba entre nosotras, ya que había querido ir a consulta aunque fuera sólo para dormir. Me dijo que, por primera vez, sentía que alguien la ayudaba a cargar su pesada carga, alguien que creía que lo que le pasaba no era pura invención de su mente.

\section{EL LADO OSCURO DE LA MENTE}

No pasó mucho tiempo para que me diera cuenta que estas sesiones presagiaban, de manera ominosa, la aparición evidente y aplastante de la parte oscura de su mente. Un día, se apareció María con el rostro impactado, congelado: "Algo perdí, me dijo, y no sé qué es". A partir de ese momento, las fallas de memoria, las desconexiones, el aplanamiento afectivo comenzaron a hacerse más evidentes. En una ocasión, me comentó que había cosas que ya no podía poner en palabras. "No te preocupes, le dije, tu mirada me dice muchas cosas: a veces brilla mostrando satisfacción o se pone opaca cuando tu mente está distante; en ocasiones adquiere un brillo penetrante y misterioso que me pone en contacto con ese mundo de horror del que no puedes hablar y al que no se me permite entrar. ¿Recuerdas, María, el videojuego donde una niña era perseguida por monstruos y pudo encontrar una "ruta secreta" para salir despistando al monstruo?. Al igual que esa chica, María, siento que podemos encontrar una ruta secreta para entrar a ese mundo: todo lo que hablas y no hablas, tus distanciamientos, tus silencios, tus secretos, tu mirada, me hablan de ese otro mundo. ¿Tiene algo de lógica lo que te digo?" Asiente, tímidamente. "¿Crees que tengo una bola de cristal?" Para mi sorpresa responde: "No, sé que lo saca de lo que pasa aqui". "Sí, así es María", le digo sonriendo. "Lo saco del lienzo simbólico que hemos pintado tú y yo -del que hemos hablado muchas veces- $y$ que está en nuestras memorias". 


\section{UNA VIÑETA DEL SEGUNDO AÑO DE TRABAJO.}

"¿Cómo estás María?" No contesta, sólo me ve fijamente. Transcurrido un rato, me percato de que su rostro se suaviza, como si estuviera a punto de reír. Se lo digo y se alza de hombros. Comienzo, no sé por qué, a registrar visualmente su cuerpo. De pronto me doy cuenta de que, de su mano cerrada, se asoma una puntita blanca. "¿Qué es eso María?, parece un kleenex, pero no, es un papelito con el link de otra canción que quieres que escuche, ¿verdad?". Suelta una risa franca. "Encontré la pista, ¿no es cierto?. ¿Sabes cómo la encontré. Es como si hubiera hecho un test de 'encuentre las diferencias. Siempre te sientas en ese rincón, recargada en el muro, tus pies cruzados de la misma manera al igual que tus manos. Pero hoy me di cuenta que había algo diferente: algo blanco se asomaba de tus manos. ¿Querías que me diera cuenta, ¿verdad?". Reímos las dos divertidas.

\section{REFLEXIÓN}

Durante este proceso, me he llegado a sentir realmente dentro de un videojuego donde tengo que encontrar pistas, una ruta secreta, que nos permita a ambas entrar a ese mundo prohibido y podernos comunicar. A través de una comunicación no verbal, de sensaciones, miradas y posturas, de vivencias divertidas y escalofriantes, de rêveries intersubjetivos, hemos podido construir, poco a poco, un espacio de juego que le pone palabras a las vivencias aterradoras de una protagonista encerrada en un mundo de horror. En ese espacio podemos encontrarnos para intentar ponerle palabras al sinsentido.

\section{TRAS DOS AÑOS DE TRABAJO, LAS PRIMERAS LÁGRIMAS...}

A los tres días, llega muy decidida a esta sesión. "Hoy traigo cosas que platicar... no sé si puedo preguntar". "Claro que sí, María", le contesto intrigada. "Se trata de un videojuego que no terminé de contarle porque no quería que supiera el final. Me siento como la protagonista. ¿Hay tiempo de verlo?". Sus palabras me inquietan profundamente. "Claro que sí", le digo sentándome a su lado en el piso para poder verlo juntas. En la primera escena aparece la orgullosa protagonista rodeada de estrellitas que simbolizan las pistas que resolvió. Enseguida se le ve recibiendo su premio: se abre un muro y la protagonista salta al vacío: " $E l$ resultado es su muerte", me lo dice feliz, con los ojos brillantes. "Puedo entender", le digo con voz suave e impactada, "que te identifiques con la chica. Tú, como ella, no quieres salir de tu casa hacia un mundo en el que no encuentras tu lugar. "¿Por qué trajiste hoy el juego?. "No sé, al terminar la sesión pasada pensé que debía traerlo y hacerle unas preguntas..." "Si me mato, puedo pasar a un mundo mejor?". Siento que un escalofrío recorre mi cuerpo. "¿Por qué la 
pregunta?" "Porque mi mamá y toda su religión dicen que los que se suicidan no pueden ir al cielo. Muy conmovida, le digo con voz muy suave, "Mira, María, podría apoyar lo que te dice tu mamá, pero prefiero ser sincera con lo que creo". "Le agradezco su sinceridad", dice muy seria. "Creo que nuestra mente es tan pequeña que no puede contestar esa pregunta. A míme gustaría mucho, le digo emocionada, que al morir me pudiera encontrar con una hermana que murió muy chica hace muchos años, con todo el amor de mis padres y el de tres hermanos que murieron hace poco. Me gustaría mucho, María, pero, la verdad, pienso que no puedo estar segura de eso". Veo brillar sus ojos con gran intensidad y, por primera vez desde que la conozco, rodar gruesas lágrimas por sus mejillas. Se las limpio y la acaricio, también por primera vez, mientras le sigo hablando. "Puedo entender por qué te identificas con esa chica. Sé por qué me trajiste este juego". Te voy a hacer una pregunta, ¿te están diciendo las voces que te mates María?. "Quisiera, pero no puedo decirlo". "Sin embargo, me das pistas que me ayudan a entender. Pero me duele lo que entiendo, siento una tensión en el pecho, veo tus lágrimas y me duele no poder hacer más". "Antes de que te vayas quiero decirte que si decides no morir, yo voy a estar aquí acompañándote a tratar de encontrar otra salida". "Yo se lo agradezco", dice entre murmullos.

\section{UNA PALABRA FINAL}

Más de dos años han transcurrido desde estas sesiones y, sin haberlo verbalizado, se han dado cambios que considero muy significativos. El gatito de peluche que acompañaba siempre a María a las sesiones, ha cedido su sitio a un gato vivo -invitado de honor que la acompaña un día de la semana a consulta. Puedo ver con ternura, cómo lo mima y acaricia como toda una madre afectuosa. Algo también muy importante, es cómo la mirada penetrante y los juegos han cedido también su lugar a las palabras. María está verbalizando más y permitiéndome entrar, de algún modo, a su mundo prohibido.

Después de mi experiencia con esta chica, me ha ido quedando claro porqué el psicoanálisis contemporáneo ha abierto sus fronteras a otras disciplinas y formas de comunicación. Cuando faltan las palabras, María y yo hemos aprendido que es posible llegar a conocernos escuchando la música que ambas tocamos detrás de las palabras. Siento que hemos encontrado la manera de estar juntas en momentos muy intensos, buscando una chispa de luz detrás del más oscuro de los sinsentidos. 


\section{LA RECONSTRUCCIÓN DE LA HISTORIA QUE ESTÁ POR VIVIRSE².}

\section{E. ALEJANDRA PLAZA ESPINOSA}

Elisa tiene una serie de problemas en su relación matrimonial, porque tiene una necesidad de construir un mundo perfecto. Cuando se da cuenta que su relación no es perfecta, piensa que su esposo la va a dejar y se llena de rabia, que aunque trata de controlar, sale en actuaciones impulsivas. Tiene el impulso de dejarlo, porque siente que él no le da un espacio. Esta sensación proviene de ella misma, el rechazo a su esposo está disociado, del amor que siente por él.

En relación a su historia, Elisa siente que nació por accidente, la madre se embarazó de un hombre alcohólico. Pareja con la que su familia no estaba de acuerdo. Son pocos los recuerdos que Elisa tiene y es poco lo que sabe de la relación de sus padres, porque es un tema tabú en su familia. Su madre murió cuando ella tenía 11 años, así que no le pudo contar, que fue de su padre, ni cuál fue su historia. Sus padres se separaron cuando ella tenía 2 años y tiene pocos recuerdos de él. La relación con la madre fue de poco contacto emocional porque, no se conectaba con las necesidades emocionales de Elisa. Siente que no tiene un lugar en el mundo, que tiene que adaptarse a las circunstancias que ya estaban cuando llegó, por lo que no puede modificarlas. No entiende su historia. porque tiene disociado su mundo, por un lado es perfecto, donde ella es amada y por otro lado ella no fue un bebe deseado.

\section{LOS TRAUMAS DEL DESARROLLO}

Vivió el trauma de una relación muy disruptiva con su madre, ya que lo que necesitaba no era importante. De acuerdo a Bromberg (2006) estuvo expuesta a un trauma del desarrollo, que le afectó en la continuidad del self, no es un solo evento de gran intensidad, sino que el trauma se fue dando cotidianamente en la relación con su madre, por su poca empatía, que le impedía ayudarle a regular sus afectos. Esta dificultad en la conexión entre las dos subjetividades promovió una disociación en se self.

La vivencia que tiene Elisa del pasado, de no tener un lugar en el deseo de los padres existe en el presente y construye su percepción de su relación actual, de la misma forma va construyendo el futuro en el que ella siente que su pareja la va a dejar, cuando ella es quien tiene el impulso de dejarlo. De acuerdo a Seligman (2013) el sentido del tiempo como un movimiento hacia un futuro se incrusta en las experiencias personales en relación a las respuestas que espera de las otras personas. 
Su self se constituyó de partes disociadas. Una parte de rabia contra su madre por haberse muerto y no importarle qué iba a pasar con ella sola. Otra parte está constituida por la relación de amor, donde parecía que podía vivir en un mundo ideal, como una niña ideal, mientras cumpliera los deseos de su madre. Sin embargo, era una situación irreal que terminaba con el fin de semana, cuando su mamá regresaba a trabajar. Esto en el fondo significa no tener un lugar en el mundo, tiene una gran incertidumbre sobre quien es en el presente y por su futuro, porque las personas mueren y todo cambia sin que ella pueda hacer nada para controlar su self y su relación con el entorno. Una forma de compensar esta angustia es tratar de controlar, buscando quedarse en un mundo ideal, donde no puede pasar nada desafortunado, como morir.

Bromberg (2006) explica que el niño se vuelve incapaz de procesar cognitivamente los estados mentales que están cargados emocionalmente en la relación interpersonal. No puede reflexionar sobre ellos y mantenerlos como estados en conflicto que son partes de él mismo. La disociación se convierte en la solución más adaptativa para conservar la sensación de mismisidad. La necesidad del niño de amor se convierte en vergüenza y desprecio, por lo que esta necesidad se disocia y se convierte en un "no yo".

Elisa desea una familia donde las cosas sean perfectas, a través de controlar para que no la abandonen y ella sea quien abandone. No se da cuenta que se enfurece contra su esposo cuando no le mitiga la angustia. Necesita un intercambio emocional profundo, para no sentirse abandonada. Como menciona Coderch (2014), aún las emociones que parecen más superfluas, crean una sensación de estar en contacto con los demás, con la humanidad y dan un sentimiento de trascendencia.

\section{LA DISCONTINUIDAD EN EL SELFY EN EL TIEMPO}

La disociación de Elisa, repercute en un problema en el manejo del tiempo. Seligman (2013) ha planteado que la temporalidad y la intencionalidad van construyendo un sentimiento de unidad del self. La continuidad de la persona "siendo" en el tiempo se da a través. La intencionalidad se refiere a que una persona responde a la comunicación, inclusive a través de las gesticulaciones y le da una sensación de que existe, dándole un significado en el tiempo.

El self y su coherencia se va construyendo a través de la relación con el otro. Tronick (1998) plantea que los estados de consciencia se conforman a través de diadas, cada persona es un sistema self organizado abierto que crea sus propios estados de consciencia, que pueden ser expandidos a sistemas más coherentes y complejos, en colaboración con otra 
persona que es otro sistema self organizado abierto, es decir, explica la formación de los estados de consciencia por medio de la teoría de los sistema complejos. Lo que uno le devuelve al otro de lo que significa ser quien es que a su vez regresa esta información, por medio de la regulación mutua de los afectos. Los estados de consciencia individuales, al expandirse en colaboración con el otro incrementan el sentido del mundo de los sistemas individuales, dentro de un sistema diádico de consciencia.

El modelo de Espacio- Tiempo Mental de Férriz Gil y Vieta Pascual (2008) propone que la relación depende de las dimensiones de espacio y tiempo físico y psíquico. La regulación de afectos pasa por las ansiedades de la creación, la vivencia y la aprehensión del espaciotiempo mental que regulan la distancia emocional y temporal del otro, de la que los extremos son la fusión por un lado y la pérdida del vínculo por el otro. Si la persona ha internalizado un patrón de regulación mutua inadecuado, puede perder la esperanza de recobrar el contacto emocional con el otro. Sin embargo, puede regresar al momento en el que hubo una regulación emocional adecuada, funcionando con un tiempo recobrado, acercándose a entender que pasa en la relación y aceptando la posibilidad de no entender. Esta función básica permite recordar y revivir situaciones traumáticas o de desencuentro de forma que no sea preponderante la necesidad de desconectarse o la impotencia de quedarse atrapado en el pasado traumático. Para no quedarse atrapado, se requiere ir integrando en el presente lo que ha sucedido en el pasado para poder encarar el futuro. El pasado no se puede cambiar, pero sí se puede entrar en el espacio-tiempo del pasado para reescribir la historia, para influir en el espacio-tiempo de la historia que está por vivirse en el futuro inmediato.

Elisa siente que no tiene un lugar en el mundo, por lo que se adapta a las circunstancias para ser aceptada. Ahora se controla a sí misma, lo que compensa su sensación de vulnerabilidad ante la muerte, el abandono o la locura. El control sustituye a la capacidad de agencia. En lugar de que Elisa se sienta capaz de ser agente se sí misma, adueñándose de su vida, tomando decisiones para ser capaz de enfrentarse a la vida, con la incertidumbre que esto implica, lo que hace es controlar.

En el proceso de disociación, de acuerdo a Bromberg (2006), la persona divide la experiencia en islas separadas, que no se tocan por el dolor que implica conectar dichas experiencias. Para que estas islas sigan disociadas, el tiempo no debe pasar, se debe quedar congelado. En la medida que fluye el tiempo, estas islas se pueden conectar y la persona sufre, aunque tiene la esperanza de que va a entender lo que está pasando en el presente, si puede recuperar el tiempo de acuerdo a sus vivencias del pasado y salir de este momento congelado haciendo una conexión con lo que está por vivirse en el futuro. 


\section{DESORDEN EN LA SUBSECUENCIA DEL TIEMPO}

Elisa vive angustiada, siente que las cosas van a salir mal. En el fondo teme revivir el evento traumático de nacer por accidente, que no tuvo un lugar para su padre y ahora no lo tiene para su esposo. El tiempo no ha pasado, ella vive temerosa del abandono de su padre y de la muerte de su madre, esto la lleva a aferrarse a su pareja para asegurarse que no va a ser abandonada. Se presenta lo que Seligman (2013) habla en el Desorden de la subsecuencia del tiempo y sus vicisitudes: el objeto no responsivo y la sensación de vacuidad del futuro, los padres no toman en cuenta los deseos del niño, sus sentimientos y lo dejan con la sensación de que nada de lo que haga importa. Esta relación no le permite al niño tener un interjuego de vitalidad, en donde lo que diga o haga tenga una consecuencia y una respuesta de su entorno. Esta falla implica una disminución en la sensación de vitalidad y se traduce en una dificultad para tener continuidad en el self. Como consecuencia de esto, se presenta una sensación de que las cosas no cambian, por lo que pasado, presente y futuro no tienen significado. La temporalidad está colapsada o ausente, no sólo por el pasado terrible, sino por la imposibilidad de hacer cambios en el presente y en el futuro de lograr las expectativas deseadas.

Elisa sustituía la sensación de poca vitalidad, por un enojo con Jaime, que no le sostenía una imagen idealizada de la relación de pareja. Deseaba tener un control omnipotente del tiempo, de eterna conexión, que la protegía del miedo al abandono.

\section{CONEXIÓN ANALISTA - PACIENTE A TRAVÉS DE LA DISOCIACIÓN}

En las sesiones, relata los problemas que tiene con su esposo y esa narración me transporta a mi propia vida en los primeros años de matrimonio. Me venía una sensación de que si yo me hubiera dado cuenta de mis partes disociadas en ese momento de mi vida, mi historia sería diferente, tal vez no me hubiera divorciado. Ahora, estoy divorciada, pero en esos momentos, se estaba dando el proceso de separación y las cosas que narraba, me causaban un dolor muy profundo y me llevaban a pensar que si yo hubiera visto en mi vida, lo que ahora estaba trabajando con Elisa, tal vez no me hubiera separado. A veces las sesiones eran muy duras, tenía el impulso de ponerme a llorar.

Se produjo una disociación entre Elisa y yo en el que de manera inconsciente, yo buscaba que no perdiera su matrimonio. Elisa sufría y tenía un gran deseo de conservar su relación, por lo que deseaba ayudarla, con la ilusión de que mi experiencia matrimonial le apoyara a rescatar el suyo. Por la disociación, no lograba ver con claridad lo que ella esperaba de mi. Este proceso afectaba la percepción del tiempo, tanto en Elisa como en mí, había un 
Desorden de la Subsecuencia del tiempo (Seligman, 2013) por la ansiedad de perder el vínculo. Su presente se combinaba con mi pasado. Ella sentía que debía mantener su matrimonio para no perder la relación conmigo. Me idealizaba, lo que le impedía tocar la relación. Temía revivir conmigo el dolor traumático de una relación sin una conexión emocional a sus deseos y expectativas.

Es difícil hablar de las situaciones clínicas que han sido problemáticas por aspectos de la vida personal, sin embargo es una oportunidad para elaborarlas. Como menciona Coderch (2013) el esfuerzo de un analista por superarse y por ayudar más allá de sus deficiencias, ayuda al paciente a darse cuenta que el analista es un ser humano con imperfecciones y así ayuda al paciente a tolerarse a sí mismo y a las personas que ama. Pensaba en que era necesario no confundir lo que era mío con lo que era de ella, pero era una respuesta más teórica y racionalizada al inicio, en el fondo, yo seguía con la idea de que sabía que ella no se quería separar, y es cierto, pero había otra parte disociada de ella, que si deseaba la separación, para no sentirse sobrepasada con el temor que Jaime la abandonara. Como plantea Bromberg, para trabajar con la disociación, la honestidad afectiva es fundamental y se puede lograr, no tanto al decir "las cosas como son", sino a través de buscar un balance con la seguridad afectiva del paciente en la relación, con un entonamiento afectivo, más allá de un movimiento técnico. Bromberg habla de la seguridad afectiva que el paciente necesita para poder usar la honestidad afectiva, porque no siempre es posible, ni deseable decirle todo al paciente. Así mismo, el analista también necesita seguridad afectiva para poder usar el self disclosure.

\section{ESTRUCTURAS DEFENSIVAS DE ACOMODACIÓN DE ELISA ANTE EL ANALISIS}

De acuerdo a Coderch (2013) los pacientes buscan en la relación terapéutica el amor del que han carecido durante la infancia, por lo que desarrollan "estructuras defensivas de acomodación" a las exigencias y deseos de la figura de apego, para evitar ser traumatizados nuevamente. La acumulación de estos pequeños traumas, con sus padres, cuando sobrepasan la capacidad de los niños de tolerarlos, pueden ocasionar procesos de disociación. Por lo que el analista debe crear un ambiente que permita la expresión libre de sus emociones, apoyándose en la confianza que el paciente pueda tenerle. Esta forma de trabajo, podría abrir la posibilidad de analizar lo que pasaba entre Elisa y yo, como ella casi no hablaba del tratamiento, para no destruir el mundo ideal en el que nada se mueve y no pasa el tiempo.

La reconstrucción de la historia que está por vivirse tiene que ver con conectar los elementos disociados de la experiencia en el momento presente, con el objetivo de darle un nuevo sentido a las experiencias del pasado, que estaban separadas. Como lo plantea Stern (1997) que utiliza el constructivismo para plantear que en el tratamiento psicoanalítico, los 
momentos más cruciales son momentos en la relación que pasan sin ser descritos. El analista y el paciente, sin ser conscientes de ello, construyen un contexto interpersonal, que restringe qué partes de la experiencia se pueden verbalizar y con qué limitaciones. La experiencia que queda fuera de esos límites se bloquea. Estas partes que no conocemos, pero que podríamos conocer quedan disociadas. Una forma de expandir estos límites y de buscar puntos de encuentro entre las partes disociadas es captar los aspectos inconscientes de la situación interpersonal, para poder ponerlos en palabras.

Stern (1997) plantea que una experiencia que no ha sido formulada en la relación con el terapeuta se puede poner en palabras, lo que va clarificándola. A través de esta interacción, se van construyendo experiencias nuevas, emergentes en un proceso de clarificación progresiva. Se co- construye esta nueva historia a través de la construcción de una relación en el presente con la terapeuta en donde se puede hablar, pensar y sentir lo que estaba disociado.

De manera inconsciente, sentía que Elisa no perdería su matrimonio a través de mi experiencia personal, y más profundamente en la fantasía, yo no perdería mi matrimonio a través de ella. Esto representaría para ella, repetir la historia, y no tener un lugar propio en la relación terapéutica, porque ella existía en función de darme gusto de no separarse, siendo una paciente ideal, sin integrar la parte disociada en la que deseaba separarse para no vivir el dolor de la pérdida y el abandono. Ella controlaba lo que pasaba entre las dos al no hablar nada de que pasaba entre nosotras y yo controlaba lo que pasaba al buscar que no "perdiera su matrimonio". Sin hablar de lo disociado, no se podía construir un lugar para ella, en el que ella se viera a sí misma deseando mantener su matrimonio y deseando abandonar a su esposo, deseando tener una relación terapéutica ideal, donde no hubiera contacto, nada se moviera y el tiempo no pasara y al mismo tiempo desando abandonar el tratamiento. Tampoco podía construir un lugar para mí como terapeuta, respetando sus decisiones y la integración de su self, con su propio deseo de vivir en pareja o separase. El desorden en la subsecuencia del tiempo en el que hiciera lo que hiciera Elisa, nada cambiaba, la mantenía paralizada, porque no encontraba una respuesta de entendimiento de mi parte para su deseo de abandonar a Jaime y a mí.

La reconstrucción de la historia que esta por vivir Elisa tiene que ver con que se sienta aceptada por mí, a través de conectar sus partes disociadas en el presente, podría darle otra lectura a su pasado, sintiendo que tiene un lugar en el mundo. Tal vez, Elisa y yo podremos cada una en nuestra vida personal, reinterpretar nuestras narrativas con mayor coherencia. Pensando, de acuerdo a como lo ha dicho Coderch (2015), que la vida tiene un hilo, no es producto del azar, aunque este también juegue un papel, nacer por accidente como lo sentía Elisa, hacía que ella actuara de cierta forma. Dirigir su vida hasta cierto punto le permite sentir 
la seguridad de un mundo más confiable, tener sus propios deseos y encontrar su propio camino para relacionarse con su esposo y decidir si en el fondo de su corazón desea mantener o no su matrimonio. Cada una de nosotras tiene que vivir su propio proceso y darnos cuenta que estábamos conjuntando su presente con mi pasado, su self con el mío, sin un espacio personal para cada una. Cada una necesita su propio espacio. Elisa tiene que vivir sus propias desilusiones de la vida, de la relación, de su terapeuta y de sí misma para tener un espacio en el mundo.

\section{UNA NUEVA RELACIÓN PARA RECONSTRUIR MI HISTORIA CON ELISA}

El cambio en las personas se da a través de la relación, como se plantea en el psicoanálisis relacional. Mi decisión de hablar lo que sucedía en la relación terapéutica, estableció un puente de contacto emocional, para poder acercarnos y tratar de lograr un cambio. La creación de un espacio transicional entre ella y yo en el que se puede hablar de lo que pasa, nos da una identidad diferenciada y va mostrándole que la diferencia de pensamiento no necesariamente ocasiona una ruptura. El espacio transicional como puerta a la intersubjetividad explica Bromberg, es un espacio para pensar entre y sobre el paciente y el analista, un espacio relacional e individual que surge de un proceso recíproco de involucramiento activo con los estados mentales del otro, que le permite al paciente una percepción en el aquí y ahora de su self para compartir conscientemente con las experiencias incompatibles de las narrativas del self que fueron disociadas anteriormente.

Una herramienta fundamental en este proceso es la honestidad afectiva que le permita a Elisa sentir que yo estoy hablando de mi sensación en el tratamiento y con esto puedo entenderla mejor y aceptar que ella tiene un pensamiento propio. La reconstrucción de la historia que estamos por vivir Elisa y yo, a través de la construcción de un espacio transicional, espero que permita una apertura para un futuro con movimiento, que tiene que ver con los cambios en el presente, que modifican la lectura de su pasado. En donde ella se pueda visualizar como alguien que tiene un lugar para sí misma. A través de la reflexión sobre este trabajo, me he confrontado con el "no yo" de Elisa y el mío, lo que me ha permitido abrir estos espacios disociados de la relación. Este proceso está echado a andar y espero me permita abrir el conocimiento de Elisa sobre su experiencia, para poder ponerla en palabras, así como lo que sucede en la relación interpersonal entre ella y yo. 


\section{DISCUSIÓN DE LOS TRABAJOS DE MARÍA CRISTINA GÓMEZ ÁLVAREZ}

\section{YE. ALEJANDRA PLAZA ESPINOSA}

\section{DR. STEVEN H. KNOBLAUCH}

El título de este panel es: "El Espacio Transicional como Puerta de Entrada a la Intersubjetividad," pero yo lo cambiaría a: "El Uso Clínico de la Experiencia Corporalizada3 al navegar en una atmósfera de Anestesia Emocional." Tanto María Cristina como Alejandra nos ofrecen un recuento muy convincente y didáctico de su trabajo donde queda claro que la atención a los registros corporalizados se vuelve crítica en el tratamiento de pacientes que exhiben dificultades para acceder a la experiencia emocional. De los muchos teóricos relacionales que discuten el significado de la experiencia corporalizada, María Cristina escoge a Beatrice Beebe, Wilma Bucci, Philip Bromberg, Allen Schore y Joan Coderch. Si bien el trabajo de cada uno de estos investigadores y/o teóricos nos puede ayudar, de algún modo, a organizar y comprender esta clase de desafíos en el tratamiento, no debemos olvidar que durante los momentos emocionales críticos que este tipo de trabajo conlleva, a menudo resulta difícil para el analista no verse arrastrado hacia un trance disociativo (contra-transferencial) junto con su paciente. En estos periodos de trabajo, en los que nuestro pensamiento se encuentra disminuido por la intensidad de la experiencia emocional, no contamos con chalecos salvavidas teóricos (como a mí me gusta llamarlos). Posteriormente, podríamos emplearlos para narrar lo que sucedió ya sea para nuestro propio rêverie o con fines de redacción o enseñanza; pero lo que es importante reconocer es el impacto de las emociones sobre el pensamiento del analista en momentos como esos. Dicho simplemente, estos son momentos de colapso cognitivo.

De esta manera, ambas escritoras ilustran sus respectivas luchas por conectar emocionalmente a sus pacientes con el significado de lo que puede estar sucediendo de manera implícita -fuera de la conciencia- pero comunicado a través de dimensiones noverbales de la interacción (aunque a veces también en el ritmo y tono de las palabras). Alejandra utiliza la teoría contemporánea de Seligman sobre el tiempo, refiriéndose a un desorden de subsecuencia, una pérdida de conexión entre el presente y el pasado, bloqueando la entrada al futuro. Esta parece una elaboración útil en función de cómo el tiempo impacta nuestra capacidad para organizar nuestra experiencia, en este caso, claramente en términos usados por los Kleinianos -y por Ogden de una manera más provechosa para la perspectiva relacional-como la postura esquizo-paranoide. En esta forma de organización, no hay un sentido lineal del tiempo. Lo que es, siempre fue, y siempre será. 
Este sentido de las cosas puede ser emocionalmente insoportable cuando lo que es...es...fue... y será insoportablemente traumático.

En ambas ilustraciones clínicas, María Cristina y Alejandra describen pacientes que han experimentado eventos traumáticos que han dañado profundamente la vitalidad y el sentido de cohesión del self. El hecho de no sentir, de no percibir sensaciones, hace muy difícil el procesamiento de la experiencia de nuestro self en relación con los demás. Uno pierde la capacidad de percibir el propio self. Uno pierde la capacidad de percibir el propio self en relación con los otros. Uno pierde su propio sentido del self como una experiencia continua. Si alguna vez han sufrido esta pérdida en cualquier forma posible, ya sea al despertar desorientados, al embriagarse, o al sentirse abrumados a causa de una fuerte crisis o ataque emocional, es bastante posible que hayan experimentado dicha fragmentación del self. Cuando esta fragmentación -esta des-vinculación de la experiencia de su significado emocional- se pierde en el tiempo, da origen a intentos psicóticos de re-conexión.

El enorme interés que muestran estas dos talentosas analistas por entender los intentos de re-conexión de sus pacientes -a menudo lejos de la conciencia intencional de éstos- nos brinda una oportunidad de aprender. Desde el inicio, María Cristina nos ofrece una descripción clara acerca de la forma en que su paciente, el cuerpo de María, le habla sobre su lucha emocional. Yo no utilizaría el término primitivo como lo hace María Cristina. El término ha sido utilizado en la teoría del desarrollo para señalar una etapa temprana. Pero cuando la experiencia del paciente exhibe una similitud con dicha etapa, es importante darse cuenta que el paciente no es ni un infante ni un niño, posee la habilidad potencial de crear vínculos y re-presentaciones abstractas que pueden no haber sido hechas con anterioridad, particularmente con palabras. Las palabras de María Cristina en este contexto tienen un impacto importante que tal vez no tendrían en un niño que careciera de capacidad lingüística.

De esta manera, María Cristina es capaz de poner atención a la monotonía de María, a sus ojos vacíos que hablan con desesperación de distancia emocional. Pero María no es una niña. María puede entender las palabras que le ofrece su analista para comenzar a crear vínculos que podrían descongelar sus sentimientos. En este momento, tengo la fantasía de María Cristina, hablando con un tono de voz uniforme, una mirada suave y una cadencia lenta y cuidadosa al espaciar sus palabras y movimientos. De hecho, ella misma nos cuenta que, a medida que comenzó a observar y describir la cara de María, sus ojos, y la tensión de sus músculos faciales, empezó también a poner atención en el tono y el ritmo de su propia voz y en la agitación de su propio cuerpo. A medida que el tratamiento progresa, lentamente, con la atención puesta en la posibilidad de una re-traumatización, nos enteramos de la capacidad de María para irse conectando paulatinamente -si bien de manera tentativa- con sus emociones $y$, finalmente, con su posibilidad de reir y sentir dolor y aflicción. 
Alejandra entreteje la visión de Seligman, el enfoque de Bromberg sobre la disociación y el trabajo de Tronick, Gil y Pascual, para subrayar que la experiencia se forma dentro de la relación diádica y que la relación misma se construye gracias al andamiaje proporcionado por "las dimensiones física y psíquica del tiempo y del espacio". Este punto no es diferente a la perspectiva de María Cristina, pero hace la importante conexión enfatizada por Jaffe et al.- de concebir al ritmo como el entramado de emociones que, a su vez, sirven de andamiaje para el significado.

A continuación, Alejandra narra su trabajo con Elisa. Nos recuerda que Elisa experimentó ritmos de intercambio que le dieron forma al tiempo y al espacio en su experiencia diádica temprana, de una manera tal, que anestesiaron toda su experiencia del en ese contexto. Este desorden de subsecuencia, como Seligman y Plaza Espinosa lo denominan, deja a Elisa incapaz de poseer una mente propia. No logra encontrar significado porque la ausencia de respuesta por parte de los demás la obliga a protegerse contra el efecto aniquilador del abandono. Elisa lo hace por medio de la disociación. Su confusión y ambivalencia sobre sus relaciones íntimas provienen de su incapacidad para determinar cómo la hacen sentir, ya que se ha convertido en una experta en anestesia emocional.

Lo que resulta muy poderoso y útil para nosotros es el reconocimiento de Alejandra sobre cómo tuvo que luchar contra la posibilidad de verse arrastrada -ella misma- al trance disociativo (contra-transferencial). Atrapada en la posición esquizo-paranoide del tiempo colapsado, Alejandra sólo podía visualizar, inicialmente, una opción para su paciente Elisa. Yo me preguntaría qué fue lo que pasó aquí. ¿Cómo fue que Alejandra llegó a lograr este cambio crítico en su propio rêverie? ¿Cómo evolucionó de una postura de identificación rígida con Elisa a su decisión de hablar sobre su propia experiencia como una forma de liberarse ella misma $y$, en definitiva, a Elisa, de este congelamiento en pensamiento y sentimiento? Alejandra sugiere que algo sucedió al momento de empezar a escribir este ensayo. Muy bien, ése es el rêverie. Pero me pregunto qué cambió -dentro de sus ritmos internos o dentro de los ritmos de su interacción con Elisa- que pudiera haber abierto, descongelado la posibilidad de derretir este desorden de subsecuencia co-construido.

La narración de Alejandra es importante para enfatizar lo que puede suceder cuando el analista no logra el tipo de atención a los registros corporalizados que pudieran hablar del tipo de atención que María Cristina describe en su caso. El ejemplo de Alejandra tiene mayores probabilidades de ocurrir cuando la anestesia emocional flota en el aire...lo cual es frecuente con el tipo de dificultades clínicas descritas por ambas presentadoras. Todo lo que sabemos sobre el impacto interactivo -aquello sobre los que nos alertan la trans-ferencia y la contra-transferencia- no es sólo la posibilidad, sino la probabilidad -y según Odgen- la necesidad de que quedemos atrapados en el desastre emocional del paciente a fin de que 
paciente y analista podamos encontrar la forma de navegar juntos hacia la salida. Esta es una consideración fundamental que Alejandra trae a nuestra atención a través de su narración clínica, un aspecto crítico de la dinámica intersubjetiva que María Cristina no discute en su presentación. Esta es la tensión que el trabajo ejerce sobre el analista, mantenerse en contacto con su intensa experiencia emocional y cómo esta tensión puede crear una disociación en el mismo analista.

Me imagino que, a pesar de que Alejandra no pudo aportar más detalles, debido a las limitaciones de tiempo de que disponemos hoy, nos podría describir cómo -el haber reconocido, y luego compartido, su propia vulnerabilidad hacia el peso emocional del estrés que Elisa experimentaba para relacionarse- resultó catalítico para su paciente. Si Alejandra podía sentir confusión y dolor y si creía una cosa, pero cuando fue capaz de sentir y de reflexionar más a fondo cambió, entonces el tiempo podría organizarse otra vez y Elisa podría encontrar su propia capacidad para organizar de manera similar sus emociones, significados y decisiones para actuar.

Para terminar, me gustaría agradecerles a ambas presentadoras el día de hoy por compartir estos valiosos ejemplos clínicos que nos hablan de cómo nuestra participación y presencia corporalizadas pueden habitar el espacio transicional aprovechando los procesos intersubjetivos. De esta manera, los analistas podrían generar posibilidades para que sus pacientes se pudieran re-conectar a sus capacidades emocionalmente anestesiadas, en parte a través de la construcción de vínculos y conexiones que el analista sea capaz de hacer con su propio cuerpo y sus rêveries corporalizados.

\section{REFLEXIONES FINALES - MARÍA CRISTINA GÓMEZ ÁLVAREZ}

Cuando Steven menciona la necesidad de que los terapeutas quedemos atrapados en el torbellino emocional del paciente a fin de encontrar juntos una salida, me vinieron a la mente las primeras lágrimas de María. ¿Cómo explicar ese encuentro tan profundamente emotivo para las dos? ¿Qué sucedió ahí que las cosas cambiaron sensiblemente a partir de ese día? Desde la óptica que nos recuerda Steven -y que concibe el ritmo de la sesión como andamiaje de emociones y significados- yo diría que las preguntas tan directas y perturbadoras de María -al igual que el enorme temor que me invadía- fueron imponiendo un ritmo tenso, pesado a nuestra interacción. Cuando me preguntó que si se suicidaba podría pasar a un lugar mejor, sentí que el ritmo de la sesión alcanzó un clímax. La cadencia que apareció -marcada por pausas y tonos suaves- fue incrementando gradualmente las emociones. Ante su mirada honesta y expectante, sentí que yo no podía fallarle; que tenía que darle algo real frente a la confusión que vivía. Ahora recuerdo las palabras que me dijo 
en una ocasión: "Estoy cansada de este mundo ilusorio, quiero algo verdadero". Completamente atrapada en un torbellino emocional, decidí, en ese momento, dejar de lado mi papel de analista neutral, y revelarle mis más íntimas y profundas creencias, sentimientos y recuerdos dolorosos. Mi auto-revelación la siento como una violación interna de los lineamientos profesionales aprendidos, sin embargo... María me lo agradeció. Bromberg (2011) dice que la auto-revelación no sólo se permite, sino que es necesaria. Muchos autores comparten la conveniencia de revelar lo que se piensa y se siente en la sesión, pero, ¿es válido revelar información de la historia personal del terapeuta? En su opinión, debe hacerse cuando ayude a intensificar la exploración de un momento en el que dos mentes se sienten afectivamente vivas la una para la otra. Este -sentí yo- fue el caso aquel día con María.

Me gustaría finalizar con unas palabras que me escribió -hace poco- la propia María cuando le expresé mi agradecimiento por permitirme hablar de su caso: "No considero que tenga que agradecerme, creo que es al contrario, yo le agradezco por muchas cosas, entre ellas dedicarme parte de su tiempo, intentar comprenderme, escucharme, interesarse en míy todo lo referente a mí, conversar conmigo, de alguna manera romper las reglas y compartirme parte de su vida, en verdad le agradezco, gracias".

\section{REFLEXIONES FINALES - E. ALEJANDRA PLAZA ESPINOSA.}

Los comentarios de Steven hace que surjan reflexiones interesantes acerca del proceso del análisis en el tiempo. ¿Qué sucedió en mi propio rêverie que me hizo hablar de lo que sucedía en la relación entre Elisa y yo? En el momento tal vez no lo tenía tan claro, sin embargo sabía que lo que estaba pasando entre las dos nos estaba afectando, estábamos sufriendo y el hecho de no hablarlo, causaba un impasse en el tratamiento. Sabía que tenía que hacer algo con mi sensación de congelamiento en espacio y tiempo. El miedo al abandono, a que se suspendiera el tratamiento, me paralizaba. Este dolor y el miedo fueron las sensaciones que me movieron a hablar. Steven (Knoblauch, 2014) ha planteado que las dimensiones del intercambio no verbal proveen una mirada más amplia de los efectos desde los cuales se puede inferir el pasado, el presente y anticipar los contextos intersubjetivos...incrementando los puntos a través de los cuales se puede construir una narrativa con un paciente a cerca de lo que se siente ser e interactuar juntos. Esta experiencia no verbal en mi relación con Elisa fue lo que me amplío la mirada acerca de lo que había pasado y estaba pasando entre nosotras, para construir una nueva narrativa de lo que se siente ser dos personas separadas.

En el momento que presenté el trabajo fue cuando hablamos de la relación. Elisa por su propia motivación se mantuvo junto a su esposo y se embarazó para reforzar su decisión, sin embargo, dejó de ir a análisis por una amenaza de aborto. Nuevamente había una lucha 
entre la vida y la muerte, el movimiento y la parálisis. Me parece que esa lucha es un proceso que va a continuar. En ese momento logramos movernos y poner en palabras lo que estaba pasando, ese fue un paso para co-construir un lugar de diferenciación para cada una de nosotras. La distancia, el espacio y la separación ayudó a enfrentar la sensación de abandono.

En relación a mi proceso como persona y como terapeuta, han cambiado mis ritmos, los espacios, los silencios, le dan una cadencia diferente a mi relación con los pacientes. Conectarme con sus ritmos y los míos y permitir los espacios, la distancia y la ausencia en los silencios, las emociones y los afectos tiene que ver con el borde musical del diálogo terapéutico que habla Steven.

La reconstrucción de la historia que está por vivirse se relaciona con el respeto al espacio del paciente. Tenía que pasar por esa vivencia para ver lo que estaba en el inconsciente en aquel momento en la relación entre ella y yo y dejar que ocupara su espacio en sus decisiones. Finalmente, el bebé de Elisa nació, la vida se impuso ante el temor a la muerte de sus seres queridos.

Mi propia reconstrucción de lo que pasó en el tratamiento de Elisa cuando empecé a escribir el trabajo ha cambiado a pesar de que está en el pasado. Cuando reflexionábamos Cristina y yo acerca de que íbamos a escribir, a pesar de que escribimos lo que dijimos en Toronto, al escribirlo en este momento, ya tiene las transformaciones que tenemos en este presente que corresponde al futuro de aquel momento. Este futuro ha sido transformado por la relación entre Cristina, Steven y yo, además de nuestras pacientes María y Elisa.

\section{REFERENCIAS}

Avila Espada, A. (2014). Intersubjetividad y soluciones narcisistas. Del Narcisismo proactivo fuente de soluciones protésicas para la identidad y sus transformaciones. Temas de Psicoanálisis, Revista de la Sociedad Española de Psicoanálisis, No 8 Julio 2014.

Beebe B. (2002). Infant Research and Adult Treatment. NY London: The Analytic Press,

Bromberg, P. (2011). Awakening the dreamer. New York, London: Routledge, Taylor \& Francis Group,

Bucci, W., (2007). Dissociation from the Perspective of Multiple Code Theory*- Part II, Contemporary Psychoanalysis. Vol. 43. No.3.

Bucci, W. (2011). The Interplay of Subsymbolic and Symbolic Processes in Psychoanalytic Treatment: It takes two to Tango. Psychoanalytic Dialogues, 21: 45-54, 2011.

Coderch, J. (2013). Los traumatismos emocionales en la infancia y adolescencia y la necesidad de amor. Clínica e Investigación Relacional, 7 (2): 338-347. Recuperado de www.ceir.org.es ]

Coderch, J. (2014). Las emociones que parecen superfluas e innecesarias. Psicoanálisis y Humanismo. Clínica e Investigación Relacional, 8 (1): 160-179. [Recuperado de www.ceir.org.es ]. 
Coderch, J. (2014). Avances en Psicoanálisis Relacional. Madrid: Ágora Relacional.

Coderch, J. (2015). Las Experiencias Terapéuticas en el Tratamiento Psicoanalítico desde la Perspectiva de la No linealidad/complejidad. Temas de Psicoanálisis, No. 9- Enero 2015.

Coderch, J. (2015) Comunicación personal.

Ferriz, M., Vieta F. (2009). Aportaciones desde el Modelo de Espacio-Tiempo Mental al Modelo de Expansión Diádica de E. Tronick. Clínica e Investigación Relacional Vol 3 (1) 82-92

Knoblauch, S. H. (2014). The Musical Edge of Therapeutic Dialogue. New York, London: Routledge, Taylor \& Francis Group.

Schore, A. N. (2007). Review of "Awakening the Dreamer: Clinical Journeys" by Philip M. Bromberg, Psychoanalytic Dialogues, 17(5): 753-767.

Schore, A. N. (2012). The Science of the Art of Psychotherapy. New York - London: Norton \& Company.

Seligman, S. (2013). Disorders of Temporality and the Subjective Experience of Time: Unresponsive Objects and the Vacuity of the Future. Trabajo presentado en el Coloquio Internacional IIPCS . México.

Stern, Donnel. (1997). Unformulated Experience: From Dissociation to Imagination in Psychoanalysis .USA: The Analytic Press.

Tronick, E.Z.,Bruschweiler-Stern, N, Harrison, A.M., Lyons-Ruth, K., Morgan, A.M., Nahum, J.P., Sander, L. Stern, D. (1998). Dyadically Expanded States of Consciousness and the process of therapeutic Change. Infant Mental Health Journal, Vol. 19 (3) , 290-299

Original recibido con fecha: 3/4/2016 Revisado: 15/6/2016 Aceptado: 30/6/2016

NOTAS:

${ }^{1}$ El caso de esta chica lo abordé en una publicación previa http://revistamentalizacion.com/ultimonumero/los_origenes_primitivos_del_ser.pdf

${ }_{2}^{2}$ Una versión ampliada de este apartado se encuentra en el capítulo 6 del libro Emoción y Relaciones Humanas. El Psicoanálisis Relacional como Terapéutica Social. De Joan Coderch y Alejandra Plaza. Editorial Ágora Relacional.

${ }^{3}$ Nota de traductor. El término "embodied" ha sido traducido como corporalizado, corporeizado o encarnado. Hasta donde se tiene conocimiento no hay un criterio unificado. Se decidió traducirlo como corporalizado, por parecer un término que se entiende con claridad. expresa. Este material es para uso científico y profesional exclusivamente y puede contener información clínica sensible. Los editores no se responsabilizan de los contenidos de los autores. Dirigir las consultas sobre derechos y autorizaciones a ceir@psicoterapiarelacional.es 